\title{
Prioritization of Kashafrud Sub-basins in Terms of Flooding Sensitivity Based on ELECTRE-TRI Algorithm
}

\author{
Adel Sepehr ${ }^{1}$, Abolfazl Abdollahi $^{2, *}$, Abbasali Mohammadian ${ }^{3}$, Mojgan Pashaie Nejad $^{4}$ \\ ${ }^{1}$ Faculty of Natural Resources and Environment, Ferdowsi University of Mashhad (FUM), Iran \\ ${ }^{2}$ Faculty of Geography, Kharazmi University of Tehran, Iran \\ ${ }^{3}$ Faculty of Natural Resources, Yazd University, Iran \\ ${ }^{4}$ Faculty of Natural Resources, Ferdowsi University of Mashhad, Iran
}

Copyright $\bigcirc 2017$ by authors, all rights reserved. Authors agree that this article remains permanently open access under the terms of the Creative Commons Attribution License 4.0 International License

\begin{abstract}
Flooding is one of the natural disasters which have effects most areas of the country and caused the loss of life and property; therefore identifying of areas which are sensitivity to flooding is one the most important measures in reducing losses. Classification and prioritization of sub-basins the first step to counter or mitigate the effects of flooding in the drainage basins. On this basis, the purpose of this study was to classify the flooding potential of sub-basins of "Kashafrud" basin in the "Khorasan Razavi" province by the using of ELECTRE-TRI Algorithm as one of the most credible multiple criteria decision making (MCDM) classification techniques based on optimistic procedure and consistency control perspectives. To achieve this, the $1: 250,000$ topographic map and waterways map of the target area were studied and area was divided into 10 sub-basins, then 8 morph hydrological parameters affecting the flooding potential including basin's form factor, elongation ratio, circularity ratio, bifurcation ratio, drainage density, mean basin slope and area were evaluated. After the evaluation, it was found that "Mashhad" and "Torghabe" sub-basins had a high-risk of flooding because of the high value of drainage density and low value of bifurcation ratio in these areas, which both have a higher effect in flooding potential compared to other factors. Toos, Chenaran, Qazqanand ... sub-basins hada low risk of flooding because of the low values of the factors which increase the flooding potential and high values of the factors which decrease it. Results obtained from the original rankings and sensitivity analysis of the results reveals that the ELECTRE TRI method could rank the strategic options of flooding sensitivity. The results of the model in this paper indicate its ability to raise evaluation of flooding criteria in classification of alternatives based on various criteria.
\end{abstract}

Keywords Kashafrud Basin, High Risk, Low Risk, Flooding Sensitivity, Morph Hydrological Parameter

\section{Introduction}

According to the statistics, Flood is one of the 3 hydro-geo-morphological hazards, which have affected much of the country and have caused the loss of life and property; hence it is considered as one of the country's natural disasters. About 91 million hectares of the country is considered to be susceptible to flooding, In other words, 55 percent of the country is involved in the production of direct and rapid runoff and about 42 million hectares of these areas shave medium to very high risk of flooding Ilkhchi et al [1]. Evaluating the flood risk of basin areas and determining the degree of sensitivity for the flood-prone areas and also the factors affecting the creation and the intensity of flood are some of the basic strategies for flood risk management. Many studies have been carried out in Iran and other countries using qualitative and quantitative methods, to prioritize the areas which are susceptible to flooding and also to determine the vulnerability of drainage basins in terms of flooding. The following studies can be mentioned as the important research in the field of flooding potential and estimation which have been conducted inside the country.

Khosroshahi and Saghafian [2] used hydrological model HEC-HMS ${ }^{1}$ and an innovative method of repeated one by one removal of sub-basins in each runoff model of Damavand drainage basin, to calculate the total output rate of this basin by conducting flood routing technique for the major waterways without the effect of removed subbasin. In this study, the sub basin which had the greatest contribution to the flood output of the basin was identified as the sub basin which was most prone to flooding.

Farajzadeh and Nosrati [3] used multivariate regression model to identify the factors influencing flood sensitivity of Gavehrud drainage basin in the western region of Iran, and classify each sub-basin in terms of their ability to produce runoff. 
Saghafian and Frazjoo [4] used flood reaction unit method in HEC-HMS hydrologic environment to prioritize the sub-basins of Golestan dam drainage basin in terms of flooding sensitivity. The results showed that a basin with a larger area or more peak flow cannot have a much greater impact on output rate of the whole basin, but other factors such as the location of subbasins and the role of routing in the main river can be important.

Malekian et al [5] used Fuzzy AHP $^{2}$ method to conduct the zoning of Akhtarabad drainage basin in terms of flooding potential, and they concluded that the high risk zones were located in northern and southern parts of basin and low-risk areas were located in the waterways and the central parts. High-risk zones were located in areas with slopes greater than 60 percent and precipitation of $300-400 \mathrm{~mm}$. Also the suitable vegetation, developed soil, and permeability of central and downstream areas were some of the factors reducing the flooding potential.

Atayi and Shiran [6] used 13 quantitative variables in fuzzy and class cluster analysis methods to identify the homogeneous sub basins of Korunplain. In each of the clustering methods, three subbasin groups were separated from each other, showing that the results of the fuzzy and class methods were almost similar, having only a slight difference in the groups. At the end, descriptive analysis was used to study the descriptive properties of the sub basins; using this method, the sub-basins were also theoretically classified in three groups based on their flooding sensitivity, which showed similarity with clusters of quantitative method.

Ghanavati et al [7] used AHP model to conduct the zoning of Farahzad (Tehran) basin in terms of flood risk, based on the $\mathrm{NDVI}^{3}$ criteria, drainage density, distance from the river, precipitation, plan metric specifications and curvature, slope, forms, land use and lithology. The results showed that most areas with high flooding potential were located in the northern and upstream parts of this basin, and that the zones susceptible to flooding were located in areas with slopes between $60-80$ percent and precipitation of $400-1000 \mathrm{~mm}$, and that many of these areas were within 300 meters of a Farahzad waterway.

In a research by Karandish et al [8], they studied the level of flooding sensitivity in the Karun sub basins and the factors that affecting it by the simulation of integrated and semi-distributed flood management. The results showed that, the level of flooding sensitivity is not necessarily a function of the area. The results of the model sensitivity analysis based on five parameters of main waterway's slope, curve number, size, Gravelius index, and mean sub basin slope, showed that the most important factor in the sub-basins flooding was the curve number. Therefore the proper management of sub-basins land usage, as the most important parameter affecting the curve number, had an important role

2Analytical Hierarchy process

3Normalized Difference Vegetation Index in controlling the floods created in the basin.

The following are some of the major studies conducted by researchers from other countries.

Sanyal and $\mathrm{Lu}$ [9] used remote sensing and GIS based methods to create maps of flooding vulnerability in Asian monsoon areas.

Levy [10] used Multi-Criteria Decision Making (MCDM) and Decision Support Systems (DSS) methods for flood risk management and concluded that MCDM and DSS can be useful in identifying flood prone areas.

Sinha et al [11] prepared the flood hazard map of Kosi River using AHP model and data layers like geomorphology, land use, topography and population density in East India.

Qin et al [12] used AHP model to conduct the zoning of flood risk areas in highways of FuLing area in China based on geology, precipitation intensity, frequency of floods, geomorphology, and vegetation criteria. In the end, Areas around highway were divided in to 4 classes of dangerous, high sensitivity, moderate Sensitivity and low Sensitivity, which covered $11.89,41.65,32.2$, and 14.26 percent of the total area respectively.

Raju and Kumar [13] used three classification techniques of K-means Cluster Analysis (KCA), Fuzzy cluster analysis (FCA), and Conon Neural Network (KNN) on 25 drainage basins in Khairthal area in India to classify small drainage basins based on morphometric characteristics. For this purpose, 10 morphometric parameters were used for classification that included drainage density, bifurcation ratio, frequency of waterways, surface flow length, form factor, basin shape factor, elongation ratio, circularity ratio, compactness coefficient, and texture ratio. Comparative analysis of classification techniques showed that 52\% (13 sub basins) had correlation with all three methods. $68 \%$ (17 sub basins) had the highest correlation with K-means clustering and Fuzzy clustering techniques, and 64\% (16 sub basin) had the highest correlation with Fuzzy clustering and Conon network techniques, and finally $60 \%$ (15 sub basin) had the highest correlation with Conon network and $\mathrm{K}$-means clustering techniques.

In the course of using decision-making methods in flood studies in Iran, most of their searchers have mainly concentrated on the ranking method decision-making such as AHP and also linear regression ranking methods. Although, some of the out ranking methods have been briefly used in the study of natural hazards such as desertification (Sepehr and Parwian [14] but the use of these methods in flood studies are truly rare. In this study, basins flood potentials have been studied using TRI approximate dominance method. ELECTRE-TRI model is a classification method for multiple criteria decision making, which classify options based on pre-determined ranges. This classification is created by the comparison of each option with the profiles which represent the boundaries of layers $\mathrm{Yu}$ [15]. The purpose of this study is to classify the flooding potential of sub-basins of "Kashafrud" basin in the "Khorasan Razavi" province, by the use of ELECTRE-TRI Algorithm based on 
optimistic procedure and consistency control perspectives.

\section{Materials and Methods}

\subsection{Location of the Study Study}

The study area is a part of Kashafrud basin with an area of 10888.889 square kilometers. This area which includes the western part of the Kashafrud great basin is located in north East of Iran in Khorasan Razavi province. Upper limit of this area is the city of Ghouchan, and its lower limit is the city of Fareeman. From west it is limited to Binalud mountain range of Nishabur, and from east it is limited to Kalat Naderi mountain range. Geographical coordinates of the study area is 35 degrees and, 58 minutes, 5.5 seconds to 37 degrees, 3 minutes and 7.87 seconds northern latitude and 58 degrees, 22 minutes, 13.87 seconds to 60 degrees, 4 minutes, 7.87 seconds eastern longitude. Figure 1 shows the location of the study area in Khorasan Razavi province. The study area has an altitude of 2800 meters in its highest point which is located in the Chenaran sub-basin, and 900 meters in its lowest points which are located in the Qazqan, Farmad, Razavi town, and Mashhad sub-basins. The most important urban areas which are located in and around the study area are the cities of Mashhad, Binalud, Chenaran, Torghabe,
Gulbahar and Shandiz. Based on hydrological divisions, study area is comprised of 10 sub-basins which are shown in Figure 1.

\subsection{Method}

To assess the flooding sensitivity, first we divided the main basin to 10 main sub-basins include Muchenan, Tous, Chenaran, Qazqan, Razavi town, Torghabe, Mashhad, Gulbahar, Shandiz and Farmad, by using of Google Earth images and 1:250,000 topographic maps, and based on the waterways of the region. Then we used Morph hydrological parameters (criteria) affecting the flooding potential including basin's form factor, elongation ratio, circularity ratio, bifurcation ratio, drainage density, and mean basin slope to study the degree of sensitivity on flooding Alizadeh (1387). Due to variety of lithology, tectonic activities, arid and semi-arid climate, seasonal rains in Kashafrud basin many geomorphological phenomena like landslide, rill erosion, alluvium, ditches and mass movements has been created. However, due to the lack of sufficient information in relation to morphology information and the most importance of physiographic characteristics in this study these information have been used.

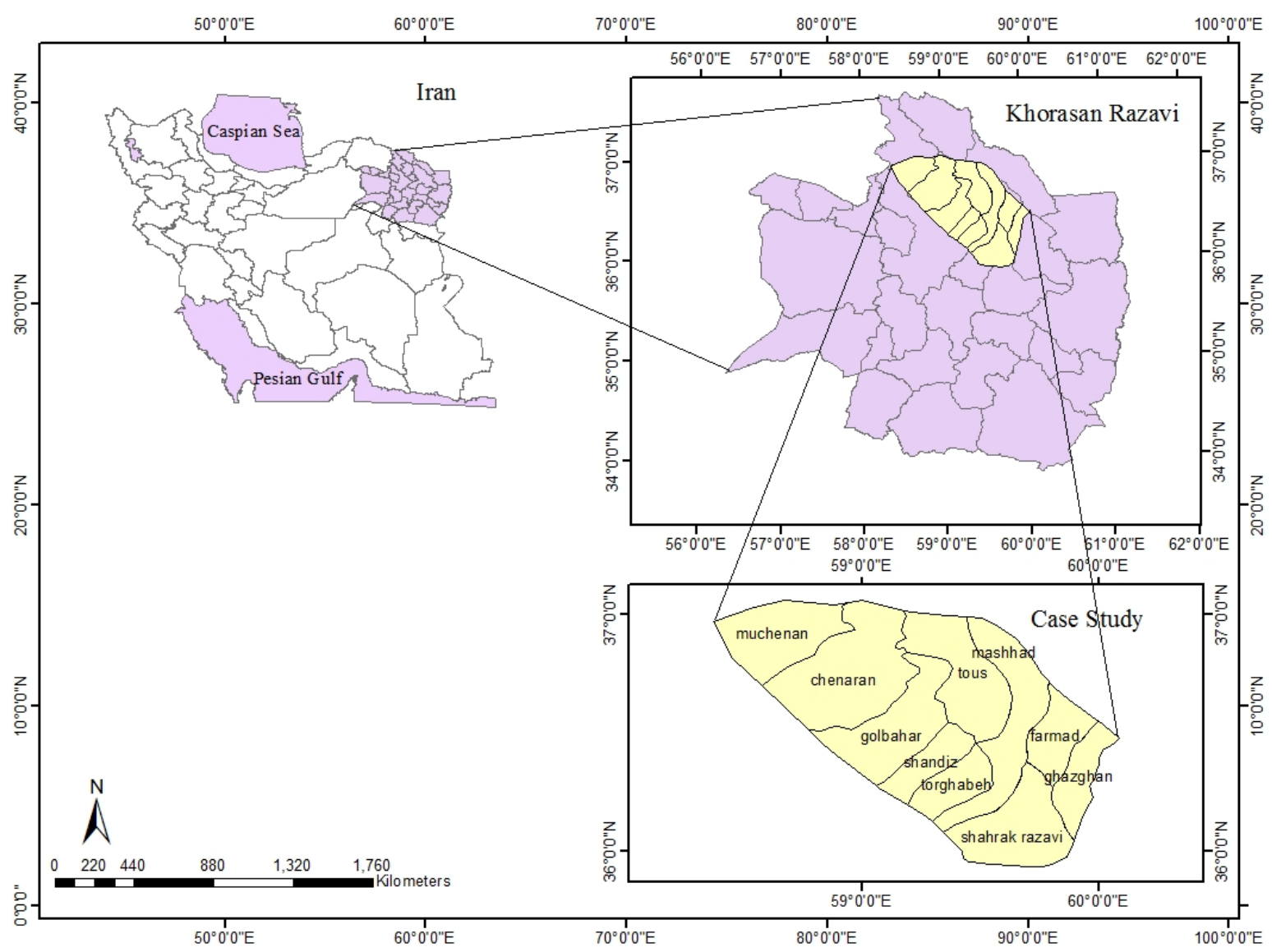

Figure 1. Location of the study study 
Form factor: Equation 1 was used to calculate the form factor of the basin.

$$
\text { F.F }=\frac{A}{\mathrm{~L}^{2}}<1
$$

In this equation (A) is the area of the basin and (L) is the length of the basin, which is the length of the straight line connecting the basin outlet point to the farthest point on the boundary of basin. If the form factor approaches 1 , basin will be more stretched and less Sensitivity in terms of flooding.

Basin Elongation: Equation 2 was used to calculate the Elongation ratio; it was developed in 1956 by Schumm.

$$
\mathrm{E}=\frac{\text { circle diameter equivalent to area of the basin }}{\text { length of the basin }}=\frac{2 \sqrt{A} / \pi}{L}
$$

In this equation $(\mathrm{A})$ is the circle diameter equivalent to area of the basin in square kilometers and (L) is the length of the basin in kilometers. This ratio is always smaller than one and if it approaches 1, basin will be more Sensitivity in terms of flooding.

Basin circularity: Equation 3 was used to calculate the circularity ratio which it was developed in 1953 by Miller.

$$
\mathrm{Rc}=\frac{12.566 \mathrm{~A}}{\mathrm{P}^{2}}=\frac{4 \pi A}{P^{2}}=
$$

Basin Area

Area of the circle with a perimeter equal to the perimeter of the basin

In this equation (A) is the area of the basin in square kilometers and $(\mathrm{P})$ is the perimeter of the basin in kilometers. This ratio is always smaller than 1 and it is close to 1 in the almost circular basins. If it approaches 1 , the basin will be more Sensitivity in terms of flooding.

Compactness coefficient: Equation 4 was used to calculate the Compactness coefficient; it was developed in 1964 by Strahler. This equation is also known as Gravelius index and is the ratio of the parameter of basin to the parameter of a circle which has an area equal to the area of basin.

$$
\mathrm{C} . \mathrm{C}=\frac{P}{2 \sqrt{(A / \pi)}}=0.282 \frac{P}{\sqrt{A}}
$$

In this equation (A) is the area of the basin in square kilometers and $(\mathrm{P})$ is the perimeter of the basin in kilometers. This ratio is close to 1 for the almost circular basins and it is about 1.5 to 2.5 for the stretched basins. If it approaches 1 , the basin will be more Sensitivity in terms of flooding.

Bifurcation ratio: it is one of the ways to study the condition of drainage network. Bifurcation ratio is the average ratio of the number of waterways in a rank (order) to the same value in a higher rank (order). It was calculated from equation 5 .

$$
\mathrm{BR}=\left(\frac{N_{1}}{N_{2}}+\frac{N_{2}}{N_{3}}+\frac{N_{3}}{N_{4}}+\cdots+\frac{N_{n-1}}{N_{n}}\right)\left(\frac{1}{n-1}\right)
$$

In this equation (BR) is the bifurcation ratio, $(\mathrm{N})$ is the number of waterways in each rank, (n) is the number of the last rank of waterway. As the bifurcation ratio decreases, lower time of concentration cause flood hydrograph to have a higher peak flow compared to other basins with equal conditions, there by the sensitivity of the basin in terms of flooding increases.

Drainage density: Drainage density is obtained by dividing the total length of the hydrographic network including tributary rivers and waterways by the area of the basin. It is correlated with the maximum flow rates of the basin. Drainage density was calculated from equation 6.

$$
\mathrm{Dd}=\frac{\sum L_{i}}{A}
$$

In this equation $(\mathrm{Dd})$ is the drainage density in kilometers per square kilometer, $\left(\mathrm{L}_{\mathrm{i}}\right)$ is the stream length in kilometers and (A) is the area of basin in square kilometers.

Mean basin slope: Basin slope has an important role in the amount of runoff, infiltration rate, the intensity of flood and amount of erosion. Its value was calculated using the equation 7 known as the Horton formula.

$$
\mathrm{S}=\frac{\mathrm{z} \sum \mathrm{l}}{\mathrm{A}}
$$

In this equation $(\mathrm{S})$ is the mean basin slope in percent, $(\mathrm{Z})$ is the vertical distance between the contour lines of the curve in kilometers, $\sum \mathrm{l}$ is the length of the contour lines of the curve located within basin in kilometers, and (A) is the area of basin in square kilometers. As the mean basin slope increases, this sensitivity of basin in terms of flooding would also increase. Table 1 shows the values calculated for each of the hydrological parameters influencing the sensitivity of the basin in terms of flooding.

Table 1. The values of the hydrological parameters (criteria) influencing the creation of flooding for each subbasin

\begin{tabular}{|c|c|c|c|c|c|c|c|c|}
\hline $\begin{array}{c}\text { Parameters } \\
\text { Subbasins }\end{array}$ & slope & $\begin{array}{c}\text { Drainage } \\
\text { density }\end{array}$ & $\begin{array}{c}\text { Bifurcation } \\
\text { ratio }\end{array}$ & $\begin{array}{c}\text { Elongation } \\
\text { ratio }\end{array}$ & $\begin{array}{c}\text { circularity } \\
\text { ratio }\end{array}$ & $\begin{array}{c}\text { Compactness } \\
\text { coefficient }\end{array}$ & $\begin{array}{c}\text { Form } \\
\text { factor }\end{array}$ & Area \\
\hline Muchenan & 2.46 & 2.8 & 132.50 & 0.87 & 0.66 & 1.22 & 0.6 & 9.1198 \\
\hline Chenaran & 2.77 & 2 & 229.37 & 0.79 & 0.60 & 1.28 & 0.49 & 2058.86 \\
\hline Golbahar & 2.56 & 3.24 & 258.64 & 0.66 & 0.43 & 1.52 & 0.34 & 1335.96 \\
\hline Shandiz & 2.55 & 2.5 & 207.76 & 0.59 & 0.56 & 1.33 & 0.27 & 536.08 \\
\hline Toos & 2.67 & 1 & 240.98 & 0.50 & 0.48 & 1.44 & 0.18 & 1318.51 \\
\hline Torghabe & 2.55 & 6 & 167.56 & 0.67 & 0.67 & 1.21 & 0.36 & 568.67 \\
\hline Mashhad & 2.47 & 2.8 & 136.29 & 0.42 & 0.24 & 2.00 & 0.14 & 1369.59 \\
\hline Razavi Town & 2.27 & 1.81 & 150.91 & 0.82 & 0.67 & 1.21 & 0.53 & 1299.02 \\
\hline Farmad & 2.26 & 1 & 223.17 & 0.53 & 0.57 & 1.31 & 0.22 & 631.72 \\
\hline Qazqan & 1.86 & 1 & 303.67 & 0.58 & 0.44 & 1.51 & 0.26 & 572.52 \\
\hline
\end{tabular}


The out ranking Electra method (TRI) was used to prioritize the study sub-basins based on the flooding sensitivity and their ability to create flood. Electra method (TRI) was first proposed in 1992 by $\mathrm{Yu}$ and subsequent versions of this method have been redeveloped since then. This method is a sorting multi criteria decision making method which classifies options (criteria) based on pre-determined ranges ( $\mathrm{Yu}$ 1992). According to figure 2, if we consider profiles $b_{1} \cdot b_{2} \ldots \cdot b_{p}$ (B set) for criteriag ${ }_{1} g_{2} 6 \ldots \cdot g_{m}(F$ set $)$, and $b_{h}$ as the upper limit of category $\mathrm{C}_{\mathrm{h}}$ and the lower limit of category $\mathrm{C}_{\mathrm{h}+1}$, then there will be a $\mathrm{P}+1$ categories. In this method, the superiority relationship (S) will be established between the options and profiles. This relationship is shown by a $\mathrm{Sb}_{h}$ or $b_{h} \mathrm{Sa}$. This means that option "a" is at least better than the profile $b_{h}$, or vice versa. Thresholds of indifference $(\mathrm{q})$ and preference $(\mathrm{P})$ constitute the internal superiority data for each criterion. These values in fact define the evaluation accuracy of options for each criterion (Yu 1992).

$q_{j}\left(b_{h}\right)$ represents the maximum difference of $g_{j}(a)-g_{j}\left(b_{h}\right)$ which represents the indifference level between the options "a" and profile " $\mathrm{b}_{\mathrm{h}}$ " for the criterion $\mathrm{g}_{\mathrm{j}}$.

$p_{j}\left(b_{h}\right)$ represents the minimum difference of $g_{j}(a)-g_{j}\left(b_{h}\right)$ which represents the preference level of the options "a" and profile " $b_{\mathrm{h}}$ " for the criterion $\mathrm{g}_{\mathrm{j}}$. Schematic representation of categories and profiles in TRI- ELECTRE method are provided in the figure (2).

To classify options, it is also necessary to calculate the concordance and discordance indices (For each pair of options, each criterion and each profile per each criterion).

A set of significant weight factors $\left(\mathrm{k}_{1} \cdot \mathrm{k}_{2}{ }^{6} \ldots \mathrm{k}_{\mathrm{m}}\right)$ and a set of intolerance threshold $\left(\mathrm{v}_{1}\left(\mathrm{~b}_{\mathrm{h}}\right), \mathrm{v}_{2}\left(\mathrm{~b}_{\mathrm{h}}\right)^{6} \ldots \mathrm{c}^{\mathrm{m}}\left(\mathrm{b}_{\mathrm{h}}\right)\right)$ are the characteristics which have a role in creating superiority relations. $v_{j}\left(b_{h}\right)$ represents the minimum difference ofg $\left(b_{h}\right)-g_{j}(a)$ which is noncompliant with $\mathrm{a} \mathrm{Sb}_{\mathrm{h}}$ equation. In this method, the indicator $\sigma\left(a, b_{h}\right) \in[0,1]$ represents the validity degree of a $\mathrm{Sb}_{\mathrm{h}}$ equation. If $\sigma\left(a, b_{h}\right) \geq \lambda$ then, $\mathrm{a} \mathrm{Sb}_{\mathrm{h}}$ equation is true. $\lambda$ Is the cutting level $(\lambda \in[0,1])$.

There are two perspectives of optimistic procedure and consistency control for doing this classification. In optimistic procedure; option " $a$ " is consecutively compared with the $b_{i}$ profiles. $b_{h}$ is the first profile which make option "a" in the equation a $\mathrm{Sb}_{\mathrm{h}}$ dependent on the $\mathrm{C}_{\mathrm{h}}+1$ category. In consistency control, option "a" is consecutively compared with the $b_{i}$ profiles. $b_{h}$ is the first profile which make option " $a$ " in the equation $b_{h}>a$ dependent on the $C_{h}$ category. As previously stated, In ELECTRE - TRI model, options eventually will be placed in predetermined classes or categories based on specific criteria. This work is done by comparing option with profiles which are actually the boundaries of classes.

In the present study, the software ELECTRE version 2 was used. In using this software, we considered flooding sensitivity parameters as the specific criteria for the classes and considered sub basins as alternatives. As previously mentioned, various factors are effective in flooding Sensitivity of a basin; some of them have a direct (increasing) relationship with flooding sensitivity which means flooding sensitivity increases with the increase of these factors; and some of them have an inverse (decreasing) relationship with flooding sensitivity which means flooding sensitivity decreases with the increase of these factors. Among the chosen factors for the prioritization of flooding sensitivity of the sub- basins, form factor, drainage density, circularity ratio, and slope had direct relationship and compactness coefficient, bifurcation ratio, and elongation ratio had inverse relationship with flooding sensitivity. Then points were given to each variable, using entropy scoring technique, and based on their degree of importance. In this regard more points were given to any variable that has a more important role in the occurrence of floods, and vice versa.

This method can also be used to determine the class importance of each these criteria. Also in this method, opinions of decision makers on the criteria are taken into account as the preference and indifference thresholds. Thresholds are selected based on the direct (positive) or inverse (negative) role in the criteria. So if intended criterion has a direct (positive) effect and its value is greater than intended threshold then it will be placed in flood prone profile. For example, in case of basin form which has a direct (positive) effect on flooding sensitivity, if the preference threshold to be 0.277 , areas with value lower than this value will have low flood sensitivity and areas with value higher than this value will have high flood sensitivity. Also if the indifference threshold to be less than 0.25 for example, it won't have any effect on flooding sensitivity anymore. 


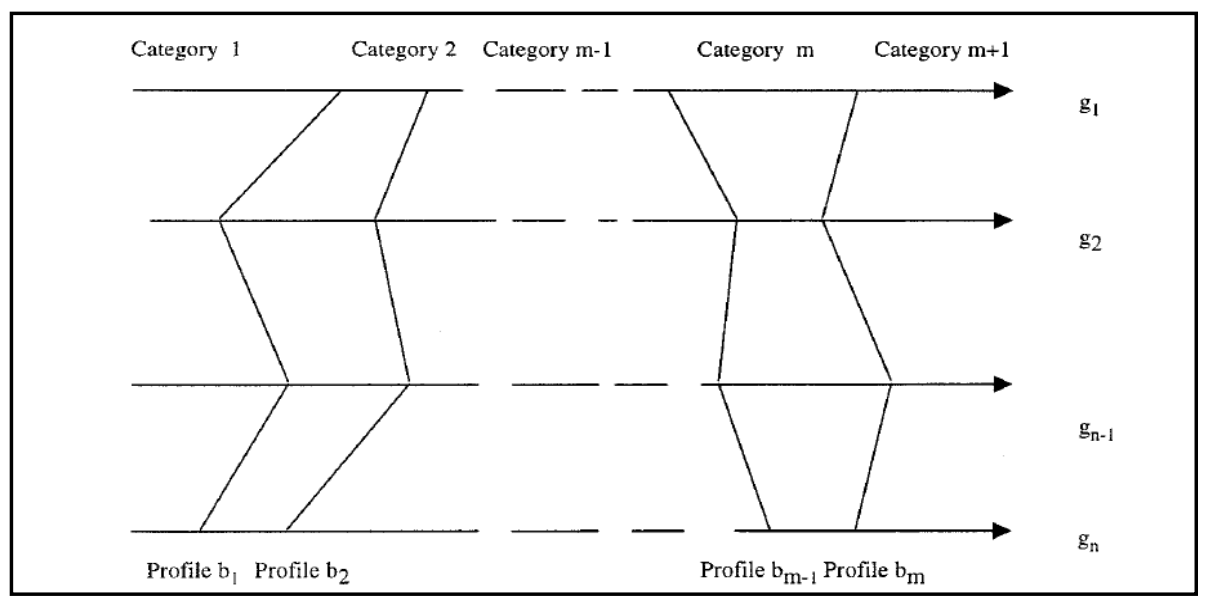

Figure 2. The method of defining categories using profiles limitations in the TRIELEC-TRE model

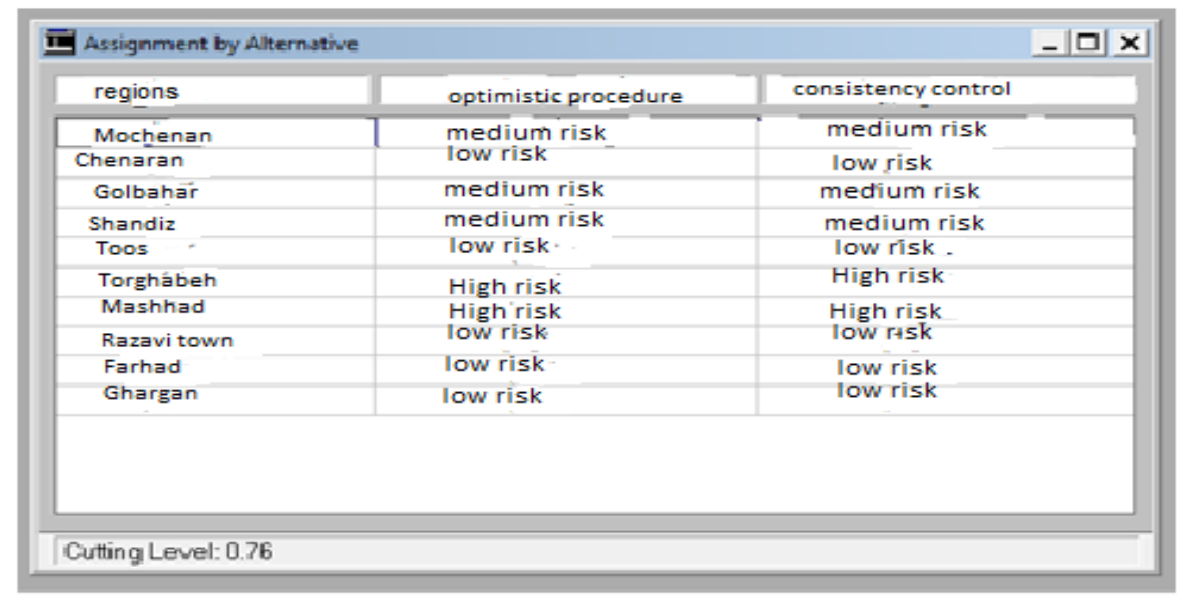

Figure 3. Classification of areas in terms of flooding sensitivity

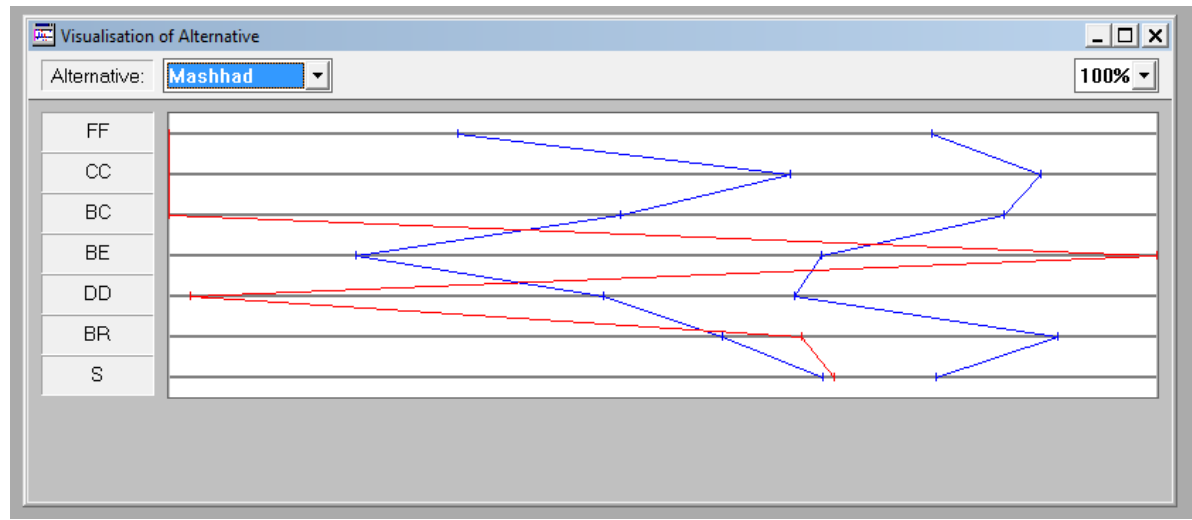

Figure 4. Mashhad sub-basin profile

\section{Results and Discussion}

As shown in Figure 3, the results of the classification of basins in terms of flooding sensitivity shows that Mashhad and Torghabe sub-basins have a high risk of flooding. It also shows the status of other sub-basins in terms of flooding sensitivity.

As shown in Mashhad profile (Figure 4), this sub-basin is considered to have a high risk of flooding, because it has a high drainage density which has a direct (positive) effect on flooding sensitivity, and also because it has a low bifurcation ratio and elongation ratio which both have an inverse (negative) effect on flooding sensitivity. The bifurcation ratio and drainage density are more effective on flooding sensitivity than other factors and they are also assigned with the highest weight, as a result the effect of other factors which could have reduced the flooding sensitivity, is neutralized, and this cause the area to be susceptible to 
flooding.

Toos sub-basin is one of the studied areas which have a low risk of flooding. As it has been shown in the Tous profile (Figure 5), this sub-basin is considered to have a low risk of flooding, because it has a low drainage density and form factor which both have a direct (positive) effect on flooding sensitivity, and also because it has a high bifurcation ratio and elongation ratio and compactness coefficient which all have an inverse (negative) effect on flooding sensitivity. As previously mentioned, the bifurcation ratio and drainage density are more effective in flooding sensitivity than other factors, and this cause this sub-basin to have a low flooding sensitivity.

According to the map of area prioritization in terms of flooding sensitivity based on consistency control perspective (Figure 6), the sub basins with high risk of flooding cover about 20 percent of the study area, and sub-basins with low and medium risk cover the remaining areas, but it must be noted that sub-basins with low and medium risk are currently in danger of becoming high risk areas, and this is because of the changing manner of land usage and also morphological changes and increasing influence of the mentioned factors in flooding sensitivity, all caused by mismanagement.

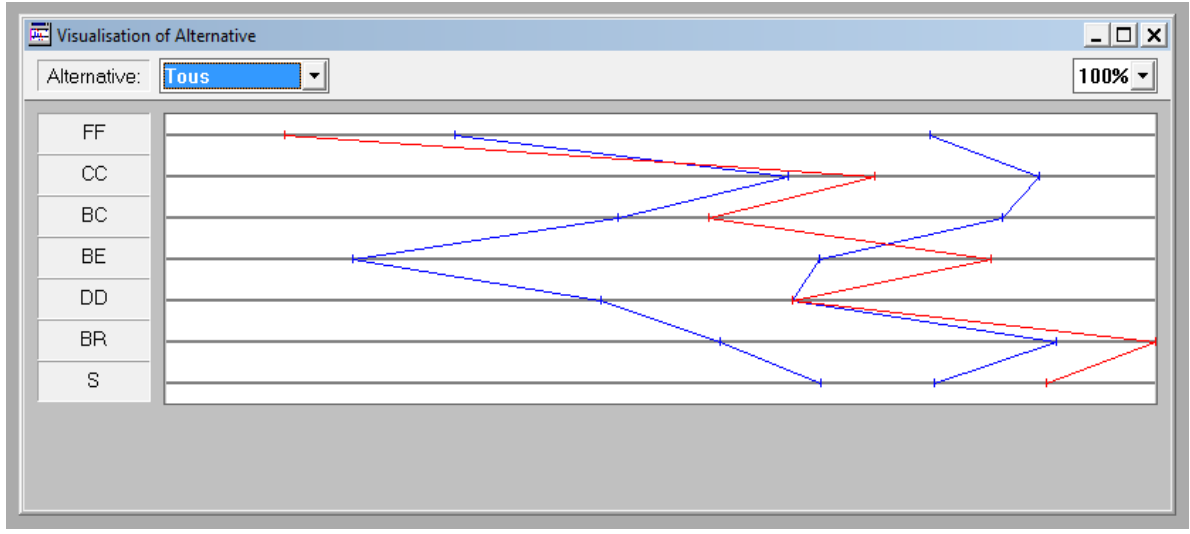

Figure 5. Tous sub-basin profile

$59^{\circ} 0^{\circ} 0^{\prime \prime} \mathrm{E}$

$60^{\circ} 0^{\circ} 0^{\prime \prime} \mathrm{E}$

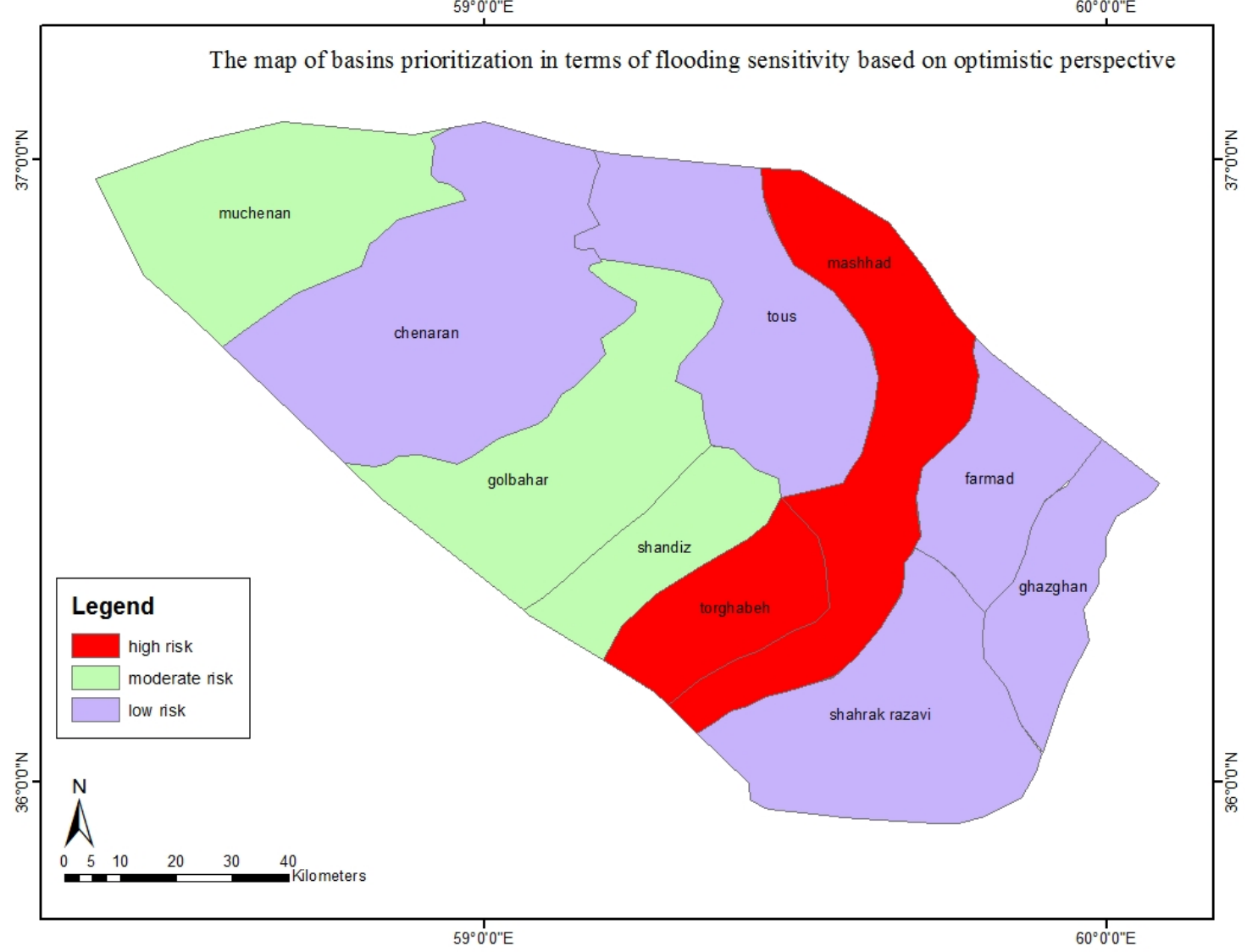

Figure 6. The map of area prioritization in terms of flooding sensitivity based on optimistic perspective 


\section{Conclusions}

The using of ELECTRE-TRI method not only exclude the necessity of fields and laboratory studies to provide the required data and to use that data for the primary rating of scenarios, but also this method consider the criteria assessment process in the stage of selecting evaluation. In fact, the model needs a set of quantitative data as inputs to be used for options on each criterion, and this data should be the results of expert judgments based on field surveys and laboratory analysis. In this study, ELECTRE-TRI method was used to prioritize the flooding sensitivity of sub basins of Kashafrud in Khorasan Razavi province. After the necessary evaluations and calculations, it was found that "Mashhad" and "Torghabe" sub-basins had a high-risk of flooding because of the high value of drainage density and low value of bifurcation ratio in these areas, which both have a higher effect in flooding potential compared to others. Toos, Chenaran, Qazqanand ... sub-basins had a low risk of flooding because of having low values in the factors which increase the flooding potential and having high values in the factors which decrease it. The results obtained from using of Electre-TRI model in this study suggests that this model according to the fuzzy classification properties of alternatives and ability to combine several criteria for each alternative and using of fuzzy logic for assigning values to handle certain alternatives with regard to the harmonized index of several criteria, can help to increase confidence in the allocation of integrated values to represent the characteristics for each criteria. The proposed Electre-TRI model structure of multi-criteria classification will be largely consistent by defining of flooding criteria. The results of the model in this paper indicate its ability to raise evaluation of flooding criteria in classification of alternatives based on various criteria. In other words, this method in addition to having good speed, targets can be realized and ultimately by creating consensus in decision-making, it can provide the final outcome with respect to all the views of decision-makers and stakeholders in the best form.

\section{REFERENCES}

[1] Ilkhchi, A., Hajabbassi, M.A., and Jalalian, A. (2002). Pasture land use change effects on Runoff. Sciences and Technology of Agriculture and Natural Resources Journal, 6 (4), 25-36.

[2] Khosroshahi, M., and Saghafian, B. (2002).The role of river in the identification and separation of flooding areas in basins. Articles Collection of Sixth International Conference on River
Engineering, Ahvaz, Chamran University.

[3] Farajzadeh, M., and Nosrati, A. (2004). Classification of flooding Sensitivity Gaveh River basin using GIS. Journal of Applied Geographical Sciences Research, (2), 255-275.

[4] Saghafian, B., and farazjoo, H. (2007). Determine and prioritize flooding areas of Golestan dam, Iranian Journal of Watershed Management Science and Engineering, 1 (1), 1-11.

[5] Malekian, A., Oftadegan Khozani, A., and Ashornejad, Gh. (2011). Classification of Flood Hazard in Watershed Scale using Fuzzy Logic (Case study: Akhtar Abad Watershed). Physical Geography Research, (4), 131-152.

[6] Ataei, H., and Shiran, M. (2012). Identifying of homogeneous hydrological basins base on effective geomorphologic factors on flood by clustering analysis (Case Study: Plain Crohn). Geography and Environmental Planning, 22 (2), 79-98.

[7] Ghanavati, A., Karam, A., and Agha Alikhani, M. (2010). Efficiency of Analytical Hierarchy Process in flooding Studies. Journal of Geography, (31), 255- 275.

[8] Karandish, F., Ebrahimi, K., and Porhemmat, J. (2012). Considering of flood intensity of Karoun's sub-basins and effective parameters in management and simulation of flood hydrograph. Water and Irrigation Management, (2), 1-12.

[9] Sanyal, J. and Lu, X. (2004). Application of Remote Sensing in Flood Management with Special Refrence to Mansoon Asia. A Review, Journal of Natural Hazards, (33), 283- 301.

[10] Levy, J.K. (2005). Multiple Criteria Decision Making and Decision Support Systems for Flood Risk Management, Journal of Stochastic Environmental Resear and Risk Assessment, (19), 438- 447.

[11] Sinha, R., Bapula, G., Singh, L., and Rath, B. (2008). Flood Risk Analysis in the Kosi River Basin, North Bihar Using Multi- Parametric Approch of Analytical Hierarchy Process (AHP). Journal of Indian Remote Sensenig, (36), 335- 349.

[12] Qin, Q., Tang, H., and Chen, H. (2011). Classification of Highway Flood-Triggering Environment for Higway in Fuling District, Changing, Journal of International Society for Optical Engineering.

[13] Raju, K., and Nagesh Kumar, D. (2011). Classification of Micro-Watersheds Based on Morphological Characteristics, Hidro-Environment Research, (5), 101-109.

[14] Sepehr, A. and Parvian, N. (2014). Sensitivity desertification mapping and prioritization strategies in Khorasan Razavi province ecosystems based on non-rating Pramseh algorithm, Earth science research, 2(8), 58-71.

[15] Yu,W. (1992). ELECTRE-TRI, Aspects Method logiqueset Manuels Dutilisation. Document Du Lamsad. Universite Paris- Daphine, 74.

[16] Alizadeh, A, (1387). Applied Hydrology (28 ${ }^{\text {th }}$ ed.). Mashhad, Iran, Emam Reza University. 